\title{
Nano Metal Dioxide Incorporated Phosphate Conversion Coatings-A Chemical Approach
}

\author{
Nilesh. S. Bagal 1,*, Vaibhav S. Kathavate ${ }^{2, *}$ and Pravin P. Deshpande ${ }^{3}$ \\ 1 Dr. Daulatarao Aher College of Engineering, Karad 415124, MS, India \\ 2 National Institute of Ocean Technology, Pallikaranai, Chennai 600100, TN, India \\ 3 College of Engineering, Shivajinagar, Pune 411005, MS, India \\ * Correspondence: nilesh.bagal.233@gmail.com, kathavate_vaibhav@rediffmail.com
}

\begin{abstract}
The present study aims at deposition of zinc phosphate coatings with the incorporation of nano Titanium dioxide particles by chemical phosphating method. Zinc phosphate coatings were developed on low carbon steel by using nano $\mathrm{TiO}_{2}$ in the standard phosphating bath. The Coated low carbon steel samples were assessed for corrosion studies using Electrochemical Impedance Spectroscopy (EIS) and Potentiodynamic Polarization techniques (TAFEL) in $3.5 \% \mathrm{NaCl}$ solution. Morphological study and Chemical composition of the coatings were analyzed by Scanning Electron Microscopy (SEM) and energy dispersive X-ray spectroscopy (EDX). Significant variations in the coating weight, porosity and corrosion resistance were observed with the addition of nano $\mathrm{TiO}_{2}$ in the phosphating bath. Corrosion rate of nano $\mathrm{TiO}_{2}$ incorporated chemical phosphate coated samples was found to be 3.5 mill inch per year (mpy) which was 4 times less than the bare uncoated low carbon steel ( 14 mpy). Electrochemical Impedance Spectroscopy studies revels in the reduction of porosity in nano $\mathrm{TiO}_{2}$ phosphate coated samples. It was found that nano $\mathrm{TiO}_{2}$ particles in the phosphating solution yielded phosphate coatings of higher coating weight, greater surface coverage and enhanced corrosion resistance than the normal zinc phosphate coatings (developed using normal phosphating bath).
\end{abstract}

Key words: chemical phosphate coating; EIS; nano $\mathrm{TiO}_{2}$; TAFEL

\section{Introduction}

Metals have tendency to corrode in their refined environment. Corrosion being the loss of electrochemical energy can be encountered by using conversion coating, sacrificial anode and by the use of some conducting polymers (Ahmad et al. 1996). Phosphate coating has been the subject of frequent studies in order to avoid corrosion. In the era of modernisation, conversion coating research has become one of the major world indices for prevention and monitoring the corrosion. Phosphate coating being as an insoluble in nature can be deposited by two methods chemical and electrochemical (T.S.N. Sankara Narayanan 2005).

Phosphate coatings have other specific features in context of corrosion protection. Phosphate coatings can afford excellent ability to corrosion resistance with optimal speed of operation and have better capacity of adhesion. Though the process was initially developed as a simple method of preventing corrosion, the changing end use of phosphate coated articles have forced the modification of the existing processes and development of innovative methods to substitute the conventional ones (S. Jagannathan et al. 2006).Few relevant studies about the effects of incorporation of nano metal dioxide and corrosion protection ability of phosphate coatings have yet been reported. One platform, by adding the nano titanium dioxide in phosphating bath with zinc oxide was investigated by (S.M.A. Shibli et al. 2011). However, low temperature phosphating processes are very slow and need to be accelerated by some means. Acceleration of the phosphating process could be achieved by chemical, mechanical and electrochemical methods. However, each of 
them has some limitations and/or detrimental effects. Chemical accelerators are the preferred choice in many instances (Vanessa de Freitas et al. 2006). It should be stressed that, while phosphate coatings always affects corrosion behaviour, its effects are not always necessarily positive. Therefore in present study, zinc phosphate coatings are obtained by incorporating nano titanium dioxide particles in the phosphating bath by chemical method. The coated samples are tested for potentiodynamic polarization studies for corrosion performance which are supported by electrochemical impedance spectroscopy (EIS) studies. Though the coatings are made by chemical phosphating method, for corrosion studies only electrochemical aspects were studied. Further the comparative studies are made for bare uncoated, normal phosphate coated and nano $\mathrm{TiO}_{2}$ incorporated phosphate coated samples.

\section{Experimental}

\subsection{Materials and Bath Preparation}

Low carbon steel substrates (AISI 1015) of $8 \mathrm{~cm} \times 2 \mathrm{~cm} \times 0.4 \mathrm{~mm}$ in size were used as the substrate material for the deposition of zinc phosphate coating by chemical method. The dust particles, oil, greasy matter present on the substrate which would inhibit coating formation were removed by cleaning with acetone. The standard phosphating bath (SURFIX ZN 603) was used for the zinc phosphate deposition. The deposition bath containing phosphate solution was prepared by incorporating nano Titanium dioxide powder $(\sim 21 \mathrm{~nm})$ which was heated up to $70^{\circ} \mathrm{C}$. The substrates were dipped in the phosphating bath for 5 minutes for zinc phosphate deposition. The phosphate specimens were rinsed with deionised water to remove the acid and the soluble salts left after phosphating. After rinsing, the specimens were dried using air dryer.

\subsection{Characterization Studies}

The surface morphology and chemical composition of the nano $\mathrm{TiO}_{2}$ incorporated phosphate coatings were further studied by using Scanning Electron Microscope and energy dispersive X-ray spectroscopy EDX respectively. The purpose for carrying the EDX is to confirm the presence of nano Titanium dioxide in the coating.

\subsection{Corrosion Studies}

Potentiodynamic polarization and Electrochemical Impedance Spectroscopy (EIS) studies were carried out using Potantiostat (GAMRY Instrument Interface 1000) at the open circuit potential. The zinc phosphate coated low carbon steel substrates were used as the working electrode, whereas saturated calomel electrode (SCE) and a platinum electrode served as the reference and counter electrodes respectively. Gamry Echem Analyst software was used for data acquisition and analysis. Polarization technique was carried out from initial potential of $-0.25 \mathrm{~V}$ to the final potential of $0.25 \mathrm{~V}$ with respect to open circuit potential. Electrochemical impedance studies were carried out in the frequency range between 10,0000 and $0.01 \mathrm{~Hz}$. The corrosion potential (Ecorr) and corrosion current density (icorr) were determined using TAFEL extrapolation method. The charge transfer resistance $\left(\mathrm{R}_{\mathrm{ct}}\right)$ and double layer capacitance $\left(\mathrm{C}_{\mathrm{dl}}\right)$ was determined from Nyquist plot by fitting the data using Gamry software.

\section{Results and Discussion}

\subsection{Chemical Phosphate Coating Deposition}

During the initial experimental work $2 \mathrm{~g} / \mathrm{L}$ of nano $\mathrm{TiO}_{2}$ was used in the phosphating bath to investigate the effect of nano $\mathrm{TiO}_{2}$ on the coating weight, morphology, chemical composition, corrosion resistance and electrochemical impedance spectroscopy. It was observed that there is significant increase in the estimated coating weight due to the incorporation of nano $\mathrm{TiO}_{2}$ particles in the phosphating bath with an immersion time of 5 minute at $70^{\circ} \mathrm{C}$ temperature. The increase in the 
coating weight and decrease in the metal dissolution can be attributed to the increase in the nucleation sites and reduction in the size of the crystal clusters of zinc phosphate deposited on the low carbon steel plate. The apparent gain in the weight of the samples, before and after coating of phosphate, provides a preliminary estimate of the amount of phosphate coated on them. It was observed that nano $\mathrm{TiO}_{2}$ incorporated phosphate coatings were heavier than the normal phosphate coating.

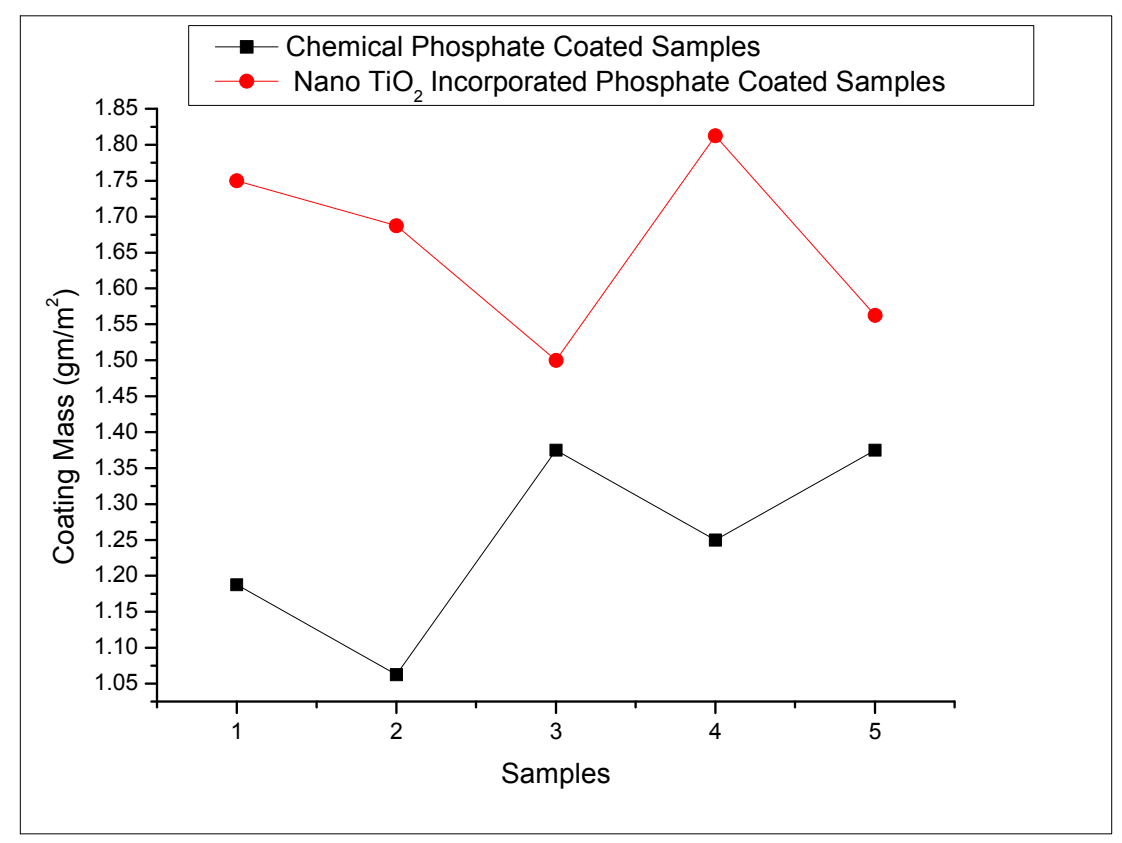

Figure 1.Comparison between coating mass.

\subsection{Characterization Studies}

The morphology of the chemical zinc phosphate coatings obtained from baths with and without nano $\mathrm{TiO}_{2}$ was carried out. The colour of the coatings was dark grey and grey for the normal phosphate coating and the phosphate coating incorporated with nano $\mathrm{TiO}_{2}$ respectively. Remarkable difference could be observed in the surface morphology of these two coatings. Compared to the normal phosphate coating surface the surface of $\mathrm{TiO}_{2}$ incorporated coating was more homogeneous. The large crystals caused better surface coverage for the coatings incorporated with nano $\mathrm{TiO}_{2}$ at the same time micro pores and cavities were obtained on the surface of both the coatings. But the number of pores was less in case of the coatings incorporated with nano $\mathrm{TiO}_{2}$ and it may be due to the surface sealing effect brought about by nano $\mathrm{TiO}_{2}$ particles. The incorporation of nano $\mathrm{TiO}_{2}$ in to the phosphating bath caused structural refinement of the crystal and also helped to achieve maximum surface coverage.
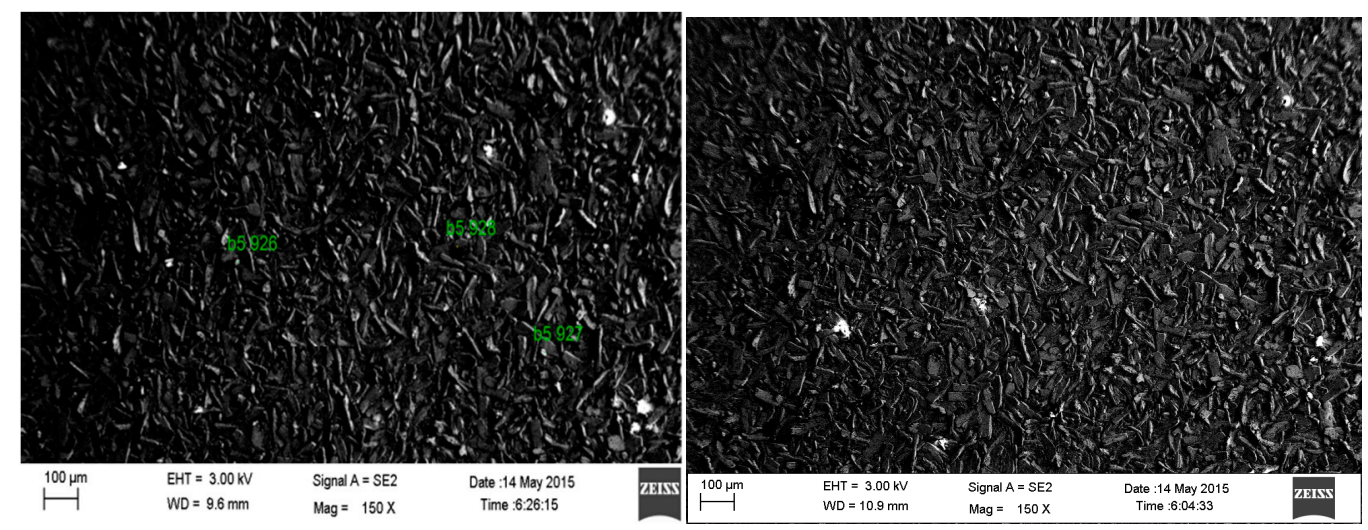
Figure 2.Scanning Electron Microscope study for chemical phosphate coatings developed using a) normal phosphating bath $\mathrm{b}$ ) phosphating bath incorporated with $2.0 \mathrm{~g} / \mathrm{L}$ nano $\mathrm{TiO}_{2}$

Energy Dispersive X-ray Spectroscopy (EDX) signals of the chemical zinc phosphate coatings developed using normal phosphating bath and phosphating bath incorporated with $2.0 \mathrm{~g} / \mathrm{L}$ nano $\mathrm{TiO}_{2}$ revels in the chemical composition of the phosphate coatings (figure 3).
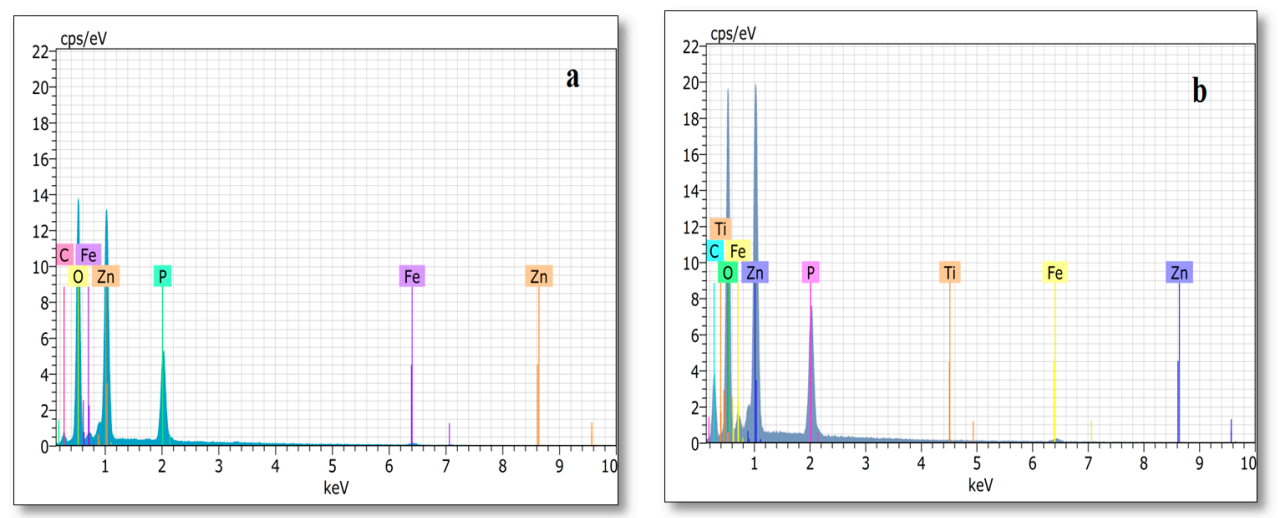

Figure 3.EDX of chemical phosphate coatings developed a) normal phosphating bath b) Phosphating bath incorporated with $2.0 \mathrm{~g} / \mathrm{L}$ nano $\mathrm{TiO}_{2}$.

From the EDX analysis it was confirmed that nano $\mathrm{TiO}_{2}$ is present in the coating developed using nano $\mathrm{TiO}_{2}$ in the phosphating bath. The chemical zinc phosphate deposition resulting from phosphating bath containing $2.0 \mathrm{~g} / \mathrm{L}$ of nano $\mathrm{TiO}_{2}$ contains more zinc than normal phosphating baths. EDX analysis revels in the significant increase in $\mathrm{Zn} / \mathrm{P}$ ratio from 3.38 to 3.45 (table 1) for the coatings developed by normal phosphating and nano $\mathrm{TiO}_{2}$ incorporated phosphate coatings which in turns lead to increase in the content of $\mathrm{Zn}_{3}\left(\mathrm{PO}_{4}\right)_{2} \cdot 4 \mathrm{H}_{2} \mathrm{O}$ when $2.0 \mathrm{~g} / \mathrm{L}$ nano TiO 2 is incorporated in the phosphating bath. The zinc phosphate coating developed using $2.0 \mathrm{~g} / \mathrm{L}$ of nano $\mathrm{TiO}_{2}$ reflect the formation of a thick coatings. But the number of pores was less in case of the coatings incorporated with nano $\mathrm{TiO}_{2}$ and it may be due to the surface sealing effect brought about by nano $\mathrm{TiO}_{2}$ particles. The incorporation of nano $\mathrm{TiO}_{2}$ in to the phosphating bath caused structural refinement of the crystal and also helped to achieve maximum surface coverage.

Table 1.Chemical composition of phosphate coated samplesobtained by EDX.

\begin{tabular}{ccccccc}
\hline Elements & Fe & O & Zn & P & Ti & Zn/P \\
\hline $\begin{array}{c}\text { Normal chemically zinc phosphate } \\
\text { coating }\end{array}$ & 15.75 & 36.32 & 27.20 & 8.06 & 00 & 3.38 \\
\begin{tabular}{c} 
Nano $\mathrm{TiO}_{2}$ incorporated coating \\
\hline
\end{tabular} & 4.59 & 38.32 & 34.30 & 9.95 & 0.13 & 3.45 \\
\hline
\end{tabular}

\subsection{Corrosion Studies}

The protectiveness of the coatings was evaluated through potentiodynamic polarization technique using $3.5 \% \mathrm{NaCl}$ solution. 


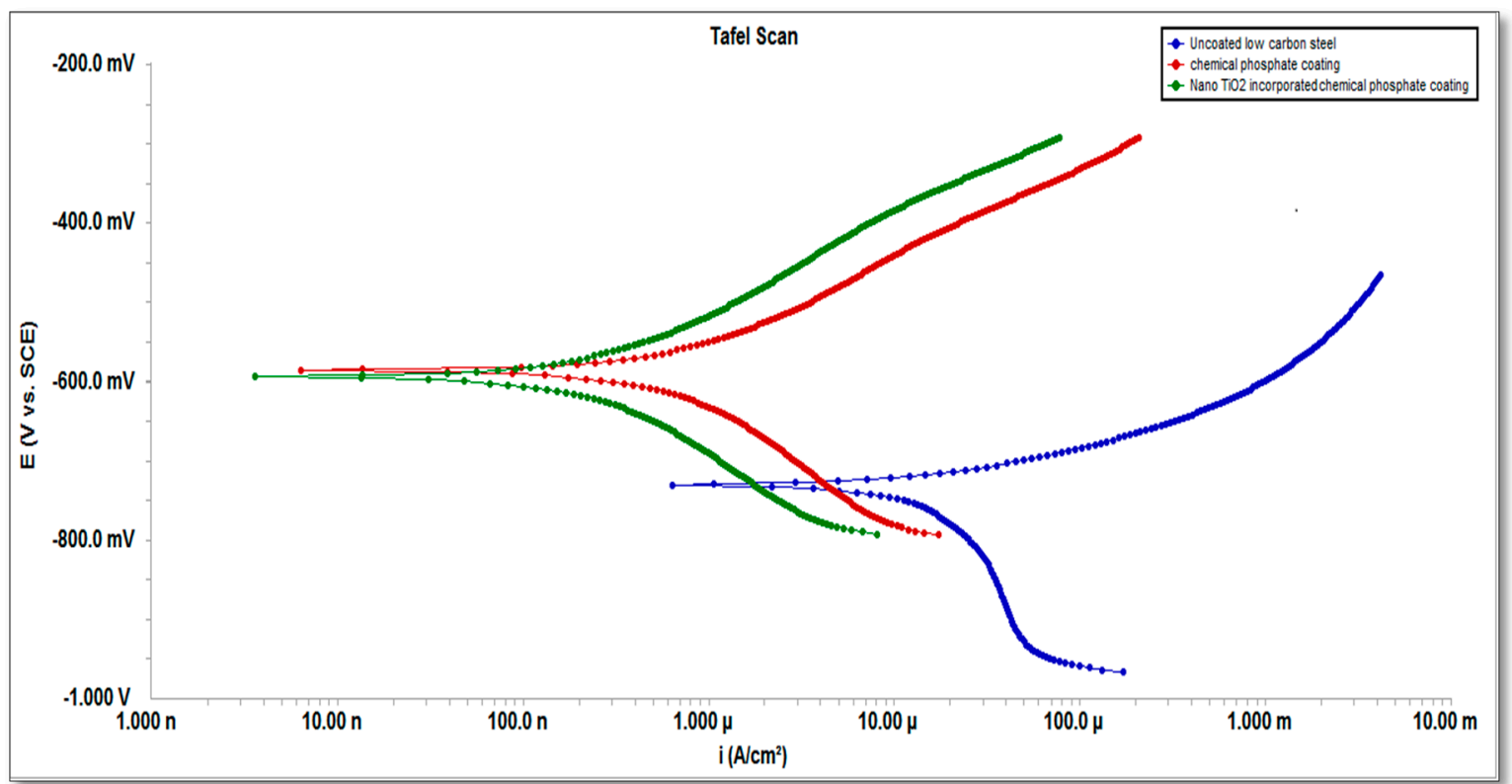

Figure 4.Potentiodynamic polarization study (TAFEL plots) for bare uncoated steel, normal phosphate coated and nano $\mathrm{TiO}_{2}$ incorporated phosphate coated steel.

It is evident that, for the substrates coated using nano $\mathrm{TiO}_{2}$ particles in the phosphating bath, the corrosion potential shifted toward positive values which reflect back in the improved corrosion resistance. It was found that the extent of shift in potential is largely a function of phosphate coating weight and the porosity of the coating. The substrate with phosphate coatings prepared from baths containing nano $\mathrm{TiO}_{2}(2 \mathrm{~g} / \mathrm{L})$ has shown the more protective corrosion environment, lowest corrosion current density and the lowest corrosion rate (table 2). Phosphate coatings are generally porous in nature, which will favour adhesion for paint film on the surface. The decrease in the corrosion current for the coatings developed using nano $\mathrm{TiO}_{2}$ particles clearly indicates that the coating is more uniform.

Table 2. Polarization parameters of uncoated and coated samples.

\begin{tabular}{ccccc}
\hline Sample & $\begin{array}{c}\text { Ecorr }_{\text {corr }} \\
(\mathbf{m V})\end{array}$ & $\mathbf{I}_{\mathbf{c o r r}}(\boldsymbol{\mu A})$ & $\mathbf{i}\left(\mathbf{A} / \mathbf{c m}^{2}\right)$ & $\begin{array}{c}\text { Corrosion Rate } \\
(\mathbf{m p y})\end{array}$ \\
\hline Uncoated low carbon steel & -731.0 & 92.70 & 0.0552 & 13.48 \\
Normal zinc phosphate coated sample & -587.0 & 2.290 & 0.0308 & 6.50 \\
${\text { Nano } \mathrm{TiO}_{2} \text { incorporated coated samples }}$ & -594.0 & 1.790 & 0.0274 & 3.58 \\
\hline
\end{tabular}

Electrochemical Impedance Spectroscopy (EIS) study of chemically zinc phosphate coated sample and nano $\mathrm{TiO}_{2}$ incorporated chemically phosphate coated samples at 0 hours of immersion in 3.5 wt. \% $\mathrm{NaCl}$ solution were carried out. 


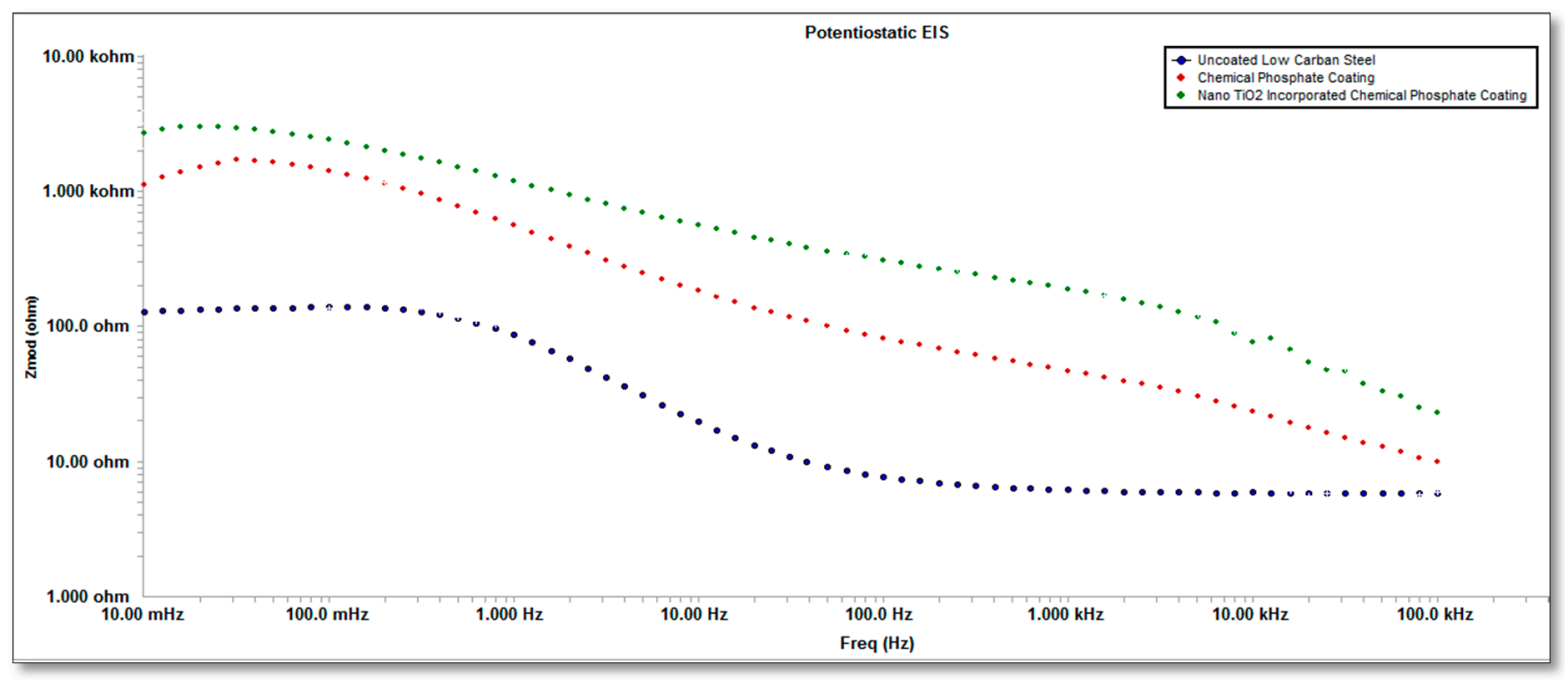

Figure 5.Bode plots of uncoated and chemically zinc phosphate coated sample.

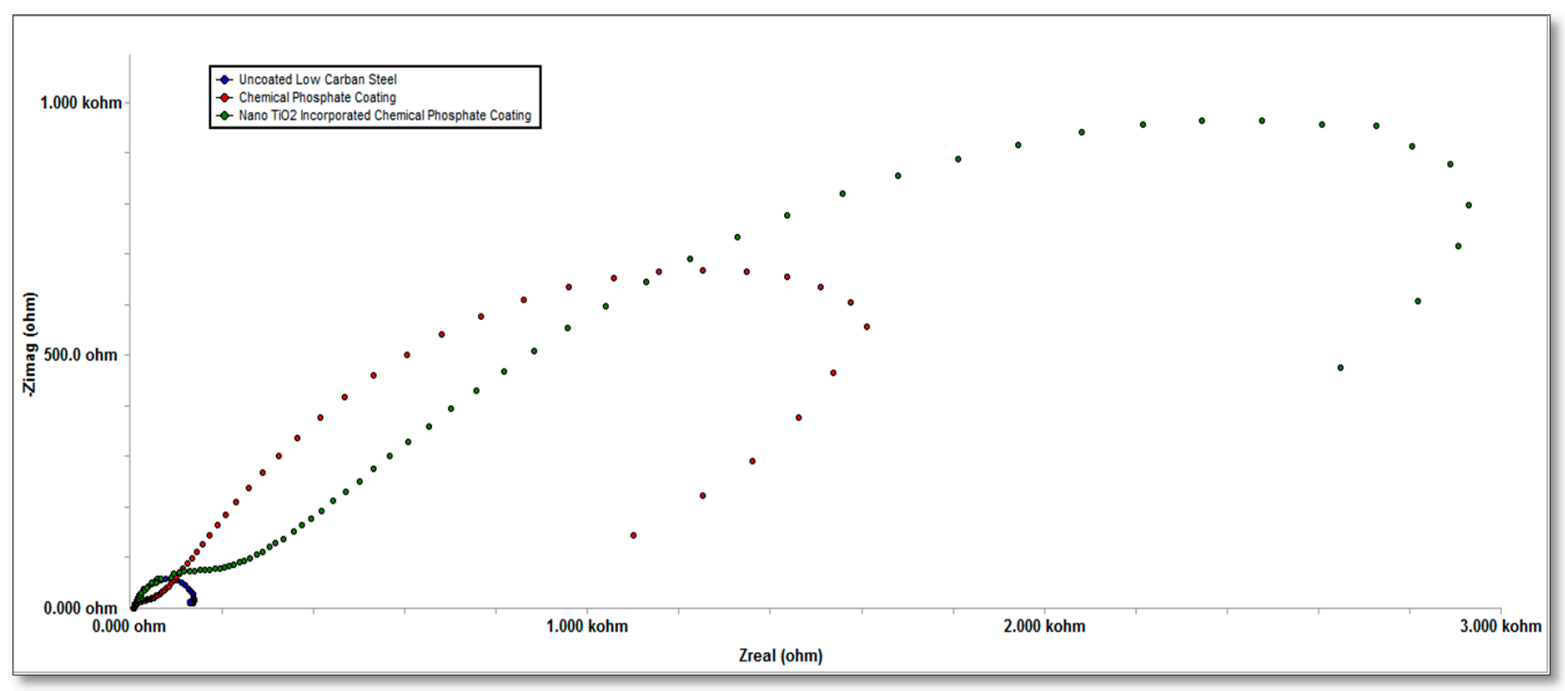

Figure 6.Nyquist plots of uncoated and coated samples.

Table 3. EIS results of uncoated and chemically zinc phosphate coated samples.

\begin{tabular}{ccccc}
\hline Sample & $\mathrm{Z}_{\text {mod }}(\boldsymbol{\Omega})$ & $\mathrm{Z}_{\text {real }}(\boldsymbol{\Omega})$ & $\mathbf{R}_{\mathrm{c}}(\boldsymbol{\Omega})$ & $\mathrm{C}_{\mathrm{c}}(\mathbf{F})$ \\
\hline Uncoated low carbon steel & 139.6 & 76.67 & 138 & 0.094 \\
Chemically zinc phosphate coated sample & 5016 & 4174 & 167.7 & 0.423 \\
Nano TiO2 incorporated coated sample & 5774 & 4589 & 607.5 & 0.005 \\
\hline
\end{tabular}

The diameter of the Nyquist plots for nano $\mathrm{TiO}_{2}$ incorporated zinc phosphate coatings is bigger compared to normal chemical phosphate coating. A high polarisation resistance $487.9 \Omega$ was obtained for the chemical zinc phosphate coatings incorporated with nano $\mathrm{TiO}_{2}$ while high coating resistance $\left(R_{c}\right)$ was observed for the chemically zinc phosphate coatings incorporated with nano $\mathrm{TiO}_{2}$, while it was as low as $138 \Omega$ in case of the uncoated low carbon steel. Again the coating capacitance of nano $\mathrm{TiO}_{2}$ incorporated chemically zinc phosphate coated sample was found out to be very low which in turns decreases the porosity in coating.

The impedance studies confirm that the corrosion behaviour of phosphated substrate using nano $\mathrm{TiO}_{2}$ particles is a much more diffusion controlled process and thereby offering a higher corrosion resistance than the normal phosphate coating. Nano $\mathrm{TiO}_{2}$ particles increase the surface coverage, 
uniformity and the thickness of the coating and decrease the porosity which improves the corrosion resistance of the phosphate coatings more than that of the normal zinc phosphate coating The impedance value is an important parameter to evaluate the anti-corrosion effect of the coating in a long time, which directly reflects the permeating ability of the corrosion medium into the coating. The larger the impedance value the more time the corrosion medium takes to pass the coating and the better the anti-corrosion properties of the coating. It was clear that the impedance of the samples covered by the phosphate coating with nano $\mathrm{TiO}_{2}$ was higher than the uncoated steel sample and general phosphate coating sample.

\subsection{Coating Porosity}

The major problem in the use of phosphate coatings is the existence of open porosity. These local defects form direct paths between the corrosive environment and the substrate. As the corrosion reactions are initiated at the coating substrate interface, determination of porosity is important to estimate the overall corrosion resistance of the coated materials. Electrochemical techniques can be used for porosity measurements and performance evaluation of coating substrate systems. The small potential difference between the substrate and the coating allows that the substrate current density be used in the porosity measurement.

The coating porosity can be evaluated using following equation proposed by Vanessa de Freitas Cunha Lins et.al.

$$
P=\frac{R_{p s}}{R_{p}} 10^{-\frac{\Delta E_{c o r r}}{\beta_{a}}}
$$

Where, $\mathrm{P}$ is the coating porosity, $\mathrm{R}_{\mathrm{ps}}$ is the polarization resistance of substrate, $\mathrm{R}_{\mathrm{p}}$ is the polarization resistance of coated substrate, $\Delta \mathrm{E}$ corr is the potential difference between the substrate and the coated substrate and $\beta$ ais the anodic TAFEL coefficient of substrate.

The electrochemical parameters were obtained by electrochemical impedance spectroscopy (EIS). Potential of substrate, coated substrate and anodic TAFEL coefficient of substrate were obtained by potentiodynamic polarization study in $3.5 \% \mathrm{NaCl}$ (table 4). Anodic TAFEL coefficient of substrate is $52.50 \mathrm{e}^{-3} \mathrm{~V} /$ decades, which is obtained from TAFEL plot of uncoated substrate.

Table 4. Electrochemical Impedance Spectroscopy (EIS) Study.

\begin{tabular}{|c|c|c|c|}
\hline Sample & $\begin{array}{l}R_{\mathrm{ps}} \\
(\Omega)\end{array}$ & $\begin{array}{l}R_{p} \\
(\Omega)\end{array}$ & $\begin{array}{c}\text { Ecorr } \\
(\mathrm{mV})\end{array}$ \\
\hline Uncoated substrate & 138 & --- & -731 \\
\hline Chemical phosphate coating & --- & 240.2 & -587 \\
\hline Nano $\mathrm{TiO}_{2}$ incorporated chemical phosphate coating & --- & 487.9 & -594 \\
\hline
\end{tabular}

Coating porosity was found to be $0.65 \%$ and $0.32 \%$ for chemical phosphate coated and nano $\mathrm{TiO}_{2}$ incorporated chemical phosphate coated substrate respectively. Significant reduction $(\sim 50 \%)$ in the coating porosity was observed in nano $\mathrm{TiO}_{2}$ incorporated chemical phosphate coating substrate as compared to normal phosphate coating. This is in agreement with the previous work as porosity is generally fairly low, of the order of $0.5-1.5 \%$ of the phosphated surface (T.S.N. Sankara Narayanan).

\section{Conclusions}

- Chemical zinc phosphate coatings were developed on low carbon steel by using nano $\mathrm{TiO}_{2}$ in the standard phosphating bath. Significant variations were observed in coating mass, porosity and corrosion resistance.

- Incorporation of nano $\mathrm{TiO}_{2}$ in bath had given the worthy results as coating porosity is reduced by $50 \%$ as compared normal phosphate coating process. 
- It can be anticipated from the EIS studies that phosphate coatings developed by the incorporation of nano $\mathrm{TiO}_{2}$ have more impedance $(5774 \Omega)$ and less coating capacitance $(0.005$ F) which in turns avoid the electrolyte penetration in the subsequent layer.

- Corrosion rate of nano $\mathrm{TiO}_{2}$ incorporated chemical phosphate coated samples was found to be 3.5 mpy which was 4 times less than the bare uncoated low carbon steel ( 14 mpy).

- To sum up, nano $\mathrm{TiO}_{2}$ particles in the phosphating solution yielded phosphate coatings of higher coating weight, greater surface coverage and enhanced corrosion resistance than the normal zinc phosphate coatings which were developed using normal phosphating bath.

Acknowledgements: The Authors want to owe their deepest sense of gratitude to Dr. N.B.Dhokey, Head of Department, Metallurgy and Materials Science, College of Engineering, Pune 411005 for providing facilities required for the completion of work. Again the moral support from Dr. S.T.Vagge, Department of Metallurgy and Materials Science, College of Engineering, Pune 411005 is also appreciated. We are very thankful to all our professors and colleague. Last but not least, our sincere gratitude to our family, because without their patience full support this was not possible.

\section{References}

1. Ahmad N. And MacDiarmid A.G. "Inhibition of Corrosion of steels with the exploitation of conducting polymers" Synthetic Metals, vol.78, (1996), pp 103-11.

2. T.S.N. Sankara Narayanan "Surface pretreatment by phosphate conversion coatings - A Review" Rev. Adv. Mater. Sci. vol. 9, (2005), pp 130-177.

3. S.M.A. Shibli, F. Chacko "Development of nano TiO2-incorporated phosphate coatings on hot dip zinc surface for good paintability and corrosion resistance" Applied Surface Science, vol. 257, (2011), pp 3111-3117.

4. P.K. Sinha, R. Feser "Phosphate coating on steel surfaces by an electrochemical method" Surface and Coatings Technology, vol. 161, (2002), pp 158-168.

5. Vanessa de Freitas Cunha Lins, Geraldo Francisco de Andrade Reis, Carlos Roberto de Araujo, TulioMatencio "Electrochemical impedance spectroscopy and linear polarizationapplied to evaluation of porosity of phosphate conversion coatings on electro galvanized steels" Applied Surface Science, vol.253, (2006), pp 28752884.

6. D. Weng, P. Jokiel, A. Uebleis, H. Boehni “Corrosion and protection characteristics of zinc and manganese phosphate coatings" Surface and Coatings Technology, vol.88, (1996), pp. 147-156.

7. M. Arthanareeswari, T.S.N. Sankara Narayanan, P. Kamaraj, M. Tamilselvi, "Influence of galvanic coupling on the formation of zinc phosphate coating", Indian Journal of Chemical Technology, vol.17, (2010), pp 167175 .

8. S.Jagannathan, T.S.N. Sankara Narayanan, K.Ravichandran, S. Rajeshwari "Formation of Zinc-Zinc Phosphate Composite Coatings by Cathodic Electrochemical Treatment" Surface and Coating Technology, vol. 200, (2006), pp 4117-4126.

9. Tamilselvi, P. Kamaraj, M. Arthanareeswari, S. Devikala "Development of nano $\mathrm{SiO}_{2}$ incorporated nano zinc phosphate coatings on mild steel" Applied Surface Science, vol. 332, (2015), pp 12-21.

10. Ruby Thomas, M.J.Umapathy "Nano Silicon Dioxide Accelerated Zinc Phosphate Conversion Coating on Mild Steel Using Decyltriethyl Ammonium Bromide as an Additive" Silicon, vol.7, (2015), pp 371-381.

11. Tamilselvi, P. Kamaraj, M. Arthanareeswari, S. Devikala "Nano zinc phosphate coatings for enhanced corrosion resistance of mild steel" Applied Surface Science, vol. 327, (2015), pp 218-225.

12. S. Jegannathan, T.K. Arumugam, T.S.N. Sankara Narayanan, K. Ravichandran, "Formation and characteristics of zinc phosphate coatings obtained by electrochemical treatment: Cathodic vs. anodic" Progress in Organic Coatings (2009) vol.65 pp229-236.

(C) 2016 by the authors; licensee Preprints, Basel, Switzerland. This article is an open access article distributed under the terms and conditions of the Creative Commons by

Attribution (CC-BY) license (http://creativecommons.org/licenses/by/4.0/). 